\title{
Erosion - deposition evaluation through hybrid DTMs derived by LiDAR and colour bathymetry: the case study of the Brenta, Piave and Tagliamento rivers
}

\author{
J. Moretto, F. Delai, E. Rigon, L. Picco, M.A. Lenzi \\ Department of Land, Environment, Agriculture and Forestry, University of Padova, Italy
}

\begin{abstract}
Risk management and flood protection are frequently assessed through geo-morphometric evaluations resulting by floods events. If we aim at elevation models with high resolutions and covering large areas, airborne LiDAR surveys can represent a good compromise among costs, time and uncertainty. The major limitation of the nonbathymetric LiDAR surveys consists in the detection of wet areas. Indeed, accounting for more than $20 \mathrm{~cm}$ of water depth, LiDAR signal increases exponentially its error. In this paper we present a comparison of the results concerning the application of a colour bathymetry methodology for the production of hybrid DTMs (HDTM). These elevation models were derived by merging LiDAR data for the dry areas and colour bathymetry for the wet areas. The methodological approach consists in a statistical regression between water depth and RGB band intensity values from contemporary aerial images. This methodology includes the use of filters in order to reduce possible errors due to the application of the model, to estimate precise "in-channel" points. The study areas are three different human impacted gravel-bed rivers of the North-East of Italy. This methodology has been applied in three sub-reaches of Brenta River, two of Piave River and two of Tagliamento River before and after relevant flood events with recurrence interval $\geq$
\end{abstract}

Correspondence: Johnny Moretto, Department of Land, Environment, Agriculture and Forestry, University of Padov, Italy.

E-mail: johnny.moretto@studenti.unipd.it

Key words: LiDAR data, DGPS survey, Colour bathymetry, Floods,Geomorphic changes, Gravel Bed River.

Acknowledgements: this research was founded by the University of Padua Strategic Research Project PRST08001, "GEORISKS, Geological, morphological and hydrological processes: monitoring, modelling and impact in NorthEastern Italy", Research Unit STPD08RWBY-004; the Italian National Research Project PRIN20104ALME4-ITSedErosion: "National network for monitoring, modeling and sustainable management of erosion processes in agricultural land and hilly-mountainous area"; and The EU SedAlp Project: "Sediment management in Alpine basis: Integrating sediment continuum, risk mitigation and hydropower", 83-4-3-AT, in the framework of the European Territorial Cooperation Programme Alpine Space 2007-2013.

(C) Copyright J. Moretto et al., 2013

Licensee PAGEPress, Italy

Journal of Agricultural Engineering 2013; XLIV(s2):e12

doi:10.4081/jae.2013.s2.e12

This article is distributed under the terms of the Creative Commons Attribution Noncommercial License (by-nc 3.0) which permits any noncommercial use, distribution, and reproduction in any medium, provided the original author(s) and source are credited.
10 years. Potentials and limitations of the applied bathymetric method, the comparison of its use in different fluvial contexts and its possibility of employment for geo-morphometric evaluations, were then tested.

DGPS control points (1841, 2638, 10473 respectively for Brenta, Piave and Tagliamento River) were finally used to evaluate the accuracy of wet areas. Results showed that, in each model, wet areas vertical errors were comparable to those featured by LiDAR data for the dry areas.

\section{Introduction}

The study of river morphology and dynamics is essential to understand the factors (natural and anthropic) determining sediment erosion, transport and deposition processes (Moretto et al., 2013a). To better analyse the magnitude of different fluvial morphological adjustments, quantitative approaches are needed. Different methods proved to be able to provide high-resolution Digital Elevation Models (DEMs) of fluvial systems. Recent studies on morphological channel changes have used passive remote sensing techniques such as digital image processing (Legleiter and Roberts, 2009), digital photogrammetry (Lane et al., 2010), active sensors including Laser Imaging Detection and Ranging (LiDAR) (Hicks et al., 2012), Terrestrial Laser Scanner (Picco et al., 2012) and acoustic methods (Rennie, 2012). The main problem related to the production of precise fluvial DTMs without using bathymetric sensors is due to the absorption of natural (solar) or artificial (LiDAR) electromagnetic radiation in the wetted channel. The survey of wetted areas can be thus approached using techniques based on the calibration of a depth-reflectance relationship of images, which can be in grey-scale (e.g. Winterbottom and Gilvear, 1997), coloured (Carbonneau et al., 2006 and Moretto et al., 2012) or multispectral (Legleiter et al., 2011). All the solutions need a field survey, contemporary to the flight, to allow the availability of calibration depth points.

The present work proposes the analysis, on the Brenta, Piave and Tagliamento Rivers, of the Moretto et al., (2012) methodology. This approach consists of a calibration of a depth-colour model to estimate channel water depths. After a filtering process, the bathymetric points for the wet areas and the LiDAR points for the dry areas will be merged to produce the final Hybrid Digital Terrain Models (HDTMs).

The specific objectives can be summarized as follows: i) analyse the results of a bathymetric approach in three different braided river systems; ii) evaluate limits and potentials of this procedure with attention to the factors significantly influencing the quality of the final results; iii) provide generic rules to minimize the possible source of errors. 


\section{Study area}

\section{Brenta river}

The Brenta River, is located in the southeastern Alps covering a drainage basin of approximately $1567 \mathrm{~km}^{2}$ and a length of $174 \mathrm{~km}$. The study reaches, located between Bassano Del Grappa and Carturo (Figure 1), have a braided and wandering morphology, active channel width ranges between $300 \mathrm{~m}$ and $800 \mathrm{~m}$ and the average slope is $0.36 \%$. Human impacts on this river were very intense; dams, gravel mining and torrent control works have caused severe effects. The average annual precipitation, mainly concentrated in spring and autumn seasons, is about $1100 \mathrm{~mm}$. Three sub-reaches $1.5 \mathrm{~km}$ long and $5 \mathrm{~km}$ apart from each other were selected and named according to the nomenclature of the nearby villages: Nove, Friola and Fontaniva (Figure 1). For more details see Moretto et al., (2013a).

\section{Piave river}

The Piave River, drainage area $4500 \mathrm{~km}^{2}$, lies in the Eastern Italian Alps. The main channel flows in the south direction for $220 \mathrm{~km}$ from its headwaters to the outlet in the Adriatic Sea, near to Venice. The climate is temperate-humid with an average annual precipitation of about $1350 \mathrm{~mm}$. Two study reaches have been selected in the middle portion of the river course (drainage area $3180 \mathrm{~km}^{2}$ at the Busche dam; Figure 1). The first one, Belluno, features a length of about $2.2 \mathrm{~km}$, whereas the second, Praloran, $3.2 \mathrm{~km}$. The river morphology in the study sub-reaches is dominated by braided and wandering channel patterns; the slope is around $0.45 \%$. For more detail see Delai et al., (2013).

\section{Tagliamento river}

The Tagliamento River is a gravel-bed river located in the Southern Alps in North-Eastern Italy (Friuli Venezia Giulia Region) and is one of the last European rivers still maintaining a high degree of naturalness. It originates at $1195 \mathrm{~m}$ a.s.l. and flows for $178 \mathrm{~km}$ to the northern Adriatic Sea, thereby forming a link corridor between the Alps and the Mediterranean zones. Its drainage basin covers $2871 \mathrm{~km}^{2}$ (Figure 1).

The hydraulic regime of the Tagliamento River is characterized by an irregular discharge and a high sedimentation load; due to the climatic and geological conditions of the upper part (annual precipitation can reach $3000 \mathrm{~mm}$ ). Two sub-reaches located near to the town of Forgaria nel Friuli were analyzed. The upstream sub-reach "Cornino" shows a predominant braided morphology, with a slope of around $0.35 \%$. Flagogna sub-reach has a predominant wandering morphology with a slope of around $0.30 \%$. For more detail see Moretto et al., (2013b).

\section{Materials and methods}

\section{Data acquisition}

Two LiDAR surveys were commissioned: the first in 2010 and the second in 2011 after the significant floods registered on November and December 2010 (Figure 2). For each LiDAR survey a point density able to generate digital terrain models with $0.5 \mathrm{~m}$ of resolution was required. LiDAR data were taken together with a series of RGB aerial photos with $0.15 \mathrm{~m}$ pixel resolution. In-channel DGPS points acquisition was performed, taking different depth. Overall, 399 (2010) and 1421 (2011) points for the Brenta River, 337 (2010) and 2301 (2011) points for the Piave River, 1107 (2010) and 9366 (2011) points for the Tagliamento River were acquired.

\section{Indirect estimates of the water level and dataset preparing}

Edges of the "wet area" through shape polygon and reliable LiDAR points able to represent the water surface elevation $(Z w l)$ in our inference zone were selected. The correspondent intensity of the colour bands and $Z w l$ were added to the points acquired in the wetted areas (DGPS wet-area survey) obtaining a shape file of points containing five fields (in addition to the spatial coordinates $\mathrm{X}$ and $\mathrm{Y}$ ): the intensity of the three colour bands, Red $(R)$, Green $(G)$, Blue $(B)$, the elevation of the channel bed (Zwet) and $Z w l$. Finally, the channel depth was calculated as $D p h=Z w l-Z w e t$.

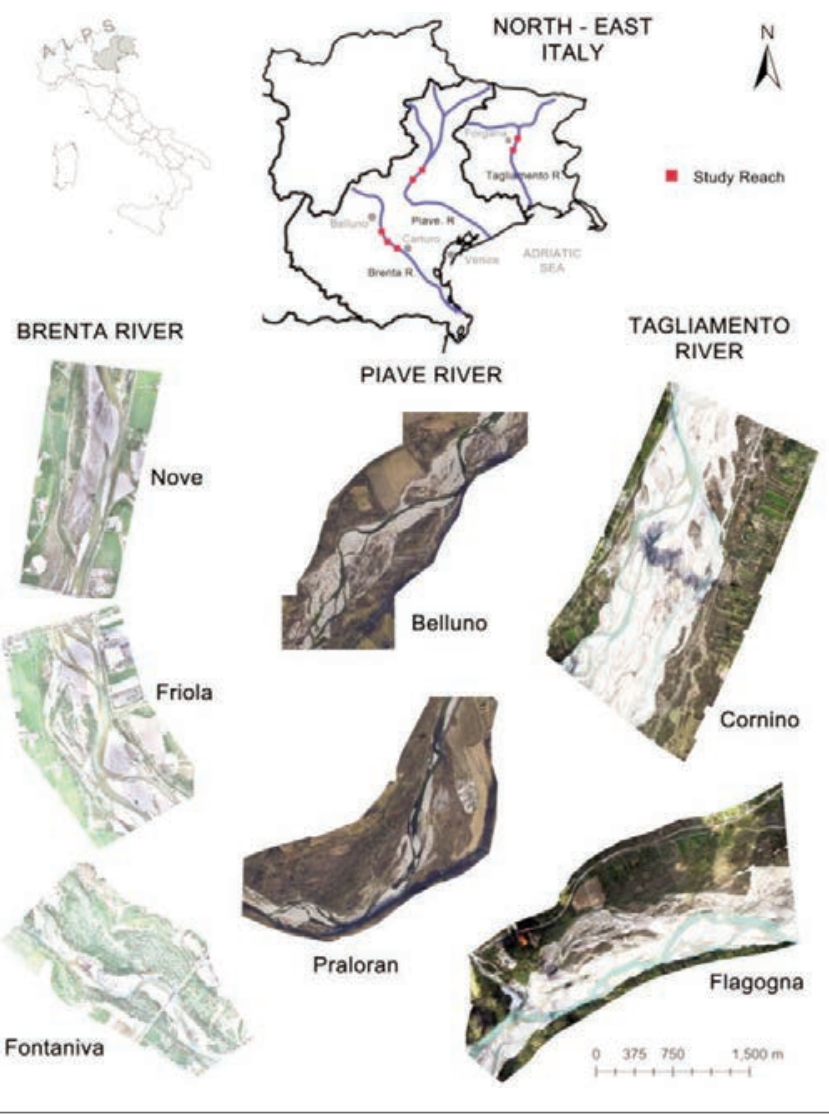

Figure 1. Study area of Brenta, Piave and Tagliamento River.

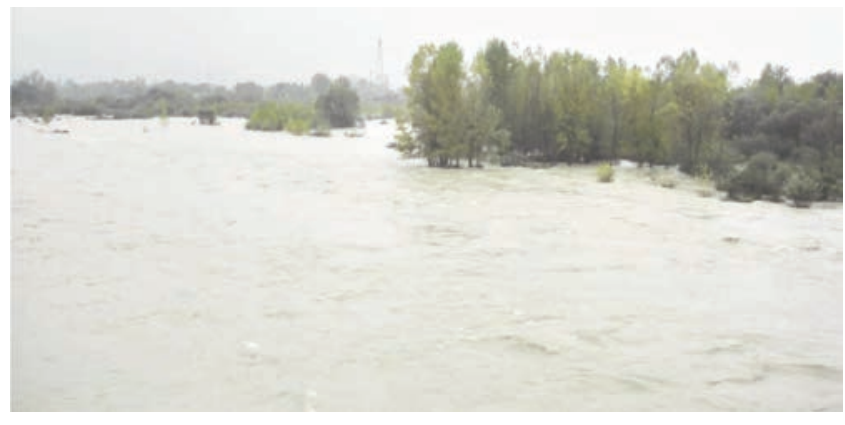

Figure 2. Floods of November 2011, Brenta River - Friola reach. 


\section{Hybrid DTM creation and validation}

The best bathymetric model was applied to the georeferenced photos (raster calculator - ArcGIS ${ }^{\circledR} 10$ ) to determine the RDph. The $R D$ ph was then filtered in order to delete incorrect points, mainly due to sunlight reflections, turbulence, and elements (wood or sediment) above the water surface (Moretto et al., 2012).

The corresponding $Z w l$ was added to the corrected points ( $D \mathrm{ph}$ model) to obtain, for each point, the estimated elevation of the river bed $(Z w e t=D p h+Z w l)$. Hybrid DTMs (HDTM) were built up with the natural neighbor interpolator, integrating Zdry points (by LiDAR) in the dry areas and Zwet points (by colour bathymetry) in the wet areas.

The final step was the validation of the HDTM models which was carried out by comparison with DGPS surveys (1841 points on Brenta River, 2638 points on Piave River, and 10473 points on Tagliamento River). The accuracy of the hybrid DTMs was estimated for wet areas considering colour bathymetry errors at different water stage levels grouped in classes incremented of $20 \mathrm{~cm}$ (see Table 1).

\section{Results}

\section{Brenta river}

The statistical regressions performed have produced the best bathymetric models for each inter-flood period. The maximum water depth estimated with an error lesser than $\pm 0.20 \mathrm{~m}$ has reached $0.80 \mathrm{~m}$ (Table 1) for this colour model:

$D p h=5.31+0.07513 R-0.1869 G-0.01475 B-0.0004582 R B+$ $0.001056 G^{2}+0.0003352 B^{2}-0.000002142 G^{3}$

where $D p h$ is the estimated water depth and R, G and B are the red, green and blue bands, respectively. A similar model structure was found on the 2011:

$D p h=-0.607+0.03508 R-0.06376 G-0.1377 B+0.002257 R G-$ $0.001096 R B+0.002303 G B-0.0007273 R^{2}-0.002956 G^{2}+0.0009993$ $B^{2}+0.000002837 G^{3}-0.00000685 B^{3}$

In this case the water depth estimated, lesser than $\pm 0.20 \mathrm{~m}$ of error has reached the same results of $0.80 \mathrm{~m}$ obtained for the 2010 (Table 1).

\section{Piave River}

From the statistical regressions performed in 2010, as in the Brenta River all the three colour bands have proved to be significantly correlated with the water depth:

$D p h=6.96+0.06222 R-0.01419 G-0.2581 B-0.0001518 R^{2}+$ $0.002002 B^{2}-0.000005091 B^{3}$

Table 1. Error analysis of depth-colour models applied at different water stages for 2010 and 2011 on Brenta, Piave and Tagliamento River.

\begin{tabular}{|c|c|c|c|c|c|c|c|c|c|}
\hline $\begin{array}{l}\text { REACH } \\
\text { Depth }\end{array}$ & \multicolumn{3}{|c|}{$\begin{array}{c}\text { Brenta } 2010 \\
\text { Dph }(\mathrm{R}, \mathrm{G}, \mathrm{B})\end{array}$} & \multicolumn{3}{|c|}{$\begin{array}{c}\text { Piave } 2010 \\
\text { Dph }(\mathrm{R}, \mathrm{G}, \mathrm{B})\end{array}$} & \multicolumn{3}{|c|}{$\begin{array}{l}\text { Tagliamento } 2010 \\
\text { Dph (R, G, B) }\end{array}$} \\
\hline $0.00-0.19$ & 0,26 & 0,22 & 107 & 0,43 & 0,28 & 7 & 0,15 & 0,11 & 232 \\
\hline $0.20-0.39$ & 0,26 & 0,24 & 87 & 0,21 & 0,16 & 42 & 0,10 & 0,09 & 327 \\
\hline $0.40-0.59$ & 0,21 & 0,20 & 75 & 0,08 & 0,15 & 81 & 0,10 & 0,09 & 275 \\
\hline $0.60-0.79$ & 0,22 & 0,18 & 59 & 0,00 & 0,17 & 70 & 0,18 & 0,13 & 184 \\
\hline $0.80-0.99$ & 0,26 & 0,15 & 32 & 0,08 & 0,18 & 50 & 0,32 & 0,19 & 64 \\
\hline $1.00-1.19$ & 0,51 & 0,21 & 20 & 0,20 & 0,23 & 38 & 0,54 & 0,22 & 15 \\
\hline $1.20-1.39$ & 0,69 & 0,14 & 13 & 0,11 & 0,22 & 27 & 0,46 & 0,21 & 9 \\
\hline $1.40-1.59$ & & & & 0,29 & 0,23 & 11 & - & - & 1 \\
\hline $1.60-1.79$ & & & & 0,13 & 0,13 & 8 & & & \\
\hline $1.80-1.99$ & & & & 0,25 & 0,33 & 3 & & & \\
\hline
\end{tabular}

$>2.00$

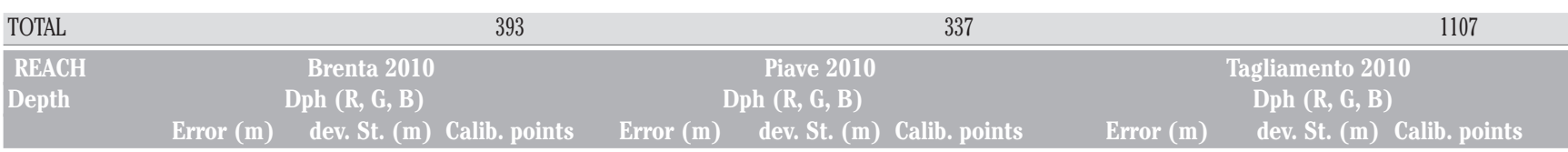

\begin{tabular}{llllllllll}
$0.00-0.19$ & 0,27 & 0,11 & 61 & 0,05 & 0,09 & 221 & 0,37 & 0,11 & 127 \\
$0.20-0.39$ & 0,18 & 0,11 & 248 & 0,04 & 0,11 & 967 & 0,21 & 0,11 & 599 \\
\hline $0.40-0.59$ & 0,13 & 0,11 & 427 & 0,19 & 0,11 & 628 & 0,14 & 0,11 & 1631 \\
$0.60-0.79$ & 0,14 & 0,13 & 343 & 0,31 & 0,13 & 301 & 0,12 & 0,10 & 2233 \\
\hline $0.80-0.99$ & 0,24 & 0,19 & 187 & 0,45 & 0,18 & 123 & 0,13 & 0,10 & 2089 \\
$1.00-1.19$ & 0,32 & 0,19 & 100 & 0,51 & 0,29 & 36 & 0,15 & 0,13 & 1419 \\
\hline $1.20-1.39$ & 0,40 & 0,13 & 35 & 0,62 & 0,30 & 8 & 0,18 & 0,16 & 755 \\
$1.40-1.59$ & 0,56 & 0,10 & 20 & 0,69 & 0,56 & 4 & 0,26 & 0,18 & 341 \\
\hline $1.60-1.79$ & & & & 0,59 & 0,70 & 7 & 0,38 & 0,21 & 123 \\
$1.80-1.99$ & & & & 1,08 & 0,54 & 6 & 0,49 & 0,19 & 39 \\
\hline
\end{tabular}


This model reaches $1.40 \mathrm{~m}$ of water depth, with an error lesser than $\pm 0.20 \mathrm{~m}$. Similarly, a regression model for 2011 was performed:

$D p h=0.83-0.004607 R+0.009665 G-0.04102 B-0.000205 R^{2}-$ $0.0006412 G^{2}+0.0002062 B^{2}+0.000002987 G^{3}+0.0005447 R G+$ $0.0005339 R B-0.000004473 R G B$

In this case, the maximum reached depth with an error lesser than $\pm 0.20 \mathrm{~m}$ is equal to $0.60 \mathrm{~m}$ (Table 1$)$.

\section{Tagliamento river}

The 2010, statistical regression has demonstrated that, as in the Brenta and Piave River all the colour bands are significantly correlated with the water depth:

$\mathrm{Dph}=-0.207+0.09 R+0.1151 G+0.007827 B+0.001573 G^{2}+$ $0.0006577 B^{2}-0.000005273 G^{3}-0.000002425 B^{3}-0.0006273 R G-$ $0.0008327 R B-0.0004865 G B+0.00000649 R G B$

This model is able to reach such as for the Brenta River $0.80 \mathrm{~m}$ of water depth with an error lesser than $\pm 0.20 \mathrm{~m}$ (Table 1). Similar results were featured for 2011:

$\mathrm{Dph}=-0.69+0.0235 \mathrm{R}-0.02822 \mathrm{G}+0.008599 \mathrm{~B}+0.000061 \mathrm{G}^{2}+$ $0.00009621 \mathrm{~B}^{2}-0.00000006799 \mathrm{R}^{3}-0.0000004239 \mathrm{~B}^{3}-0.00009157 \mathrm{RG}-$ $0.00004429 \mathrm{RB}-0.00004228 \mathrm{~GB}+0.0000005079 \mathrm{RGB}$

An example regarding the result of the model application is reported in Figure 3. From a general point of view the model seems to be able to produce a good water depth estimation comparing with the aerial photos.

This model, compared with the control points, estimates the wet area with an average error lesser than $\pm 0.20 \mathrm{~m}$ up to $1.40 \mathrm{~m}$ (Table 1 ) of water depth.

\section{Discussion}

The different water depth errors estimated from LiDAR and from the proposed colour bathymetric approach have been compared to the 2010 and 2011 Brenta, Piave and Tagliamento DGPS surveys and reported on Table 1.

The statistical analysis showed that all the three bands (R G B) and also some of the other constituent factors (interactions among bands and square and cubic terms) are significant $(\mathrm{P}<0.05)$ for each river and each year to predict the water depth.

The results confirm that more the depth increases, greater is the light adsorbed, as described by Legleiter (2012), raising the variability of $\mathrm{R}, \mathrm{G}$ and $\mathrm{B}$ colour bands. This greater variability decreases the quality of the results of the colour models. Despite this decrease in quality, an adequate number of calibration points allow to reach an acceptable error in function of the final goal.

To provide some guidelines to project the "colour bathymetry survey", the expected error associated with the depth and the calibration points was implemented in Figure 4. Four "error model" are reported, one for each river (interpolating the 2010 and 2011 error data reported in Table 1) and one that is the average "error trend" obtained by interpolating all "error data" from each river. To provide more solid general rules, suspicious points were deleted. Therefore for the 2010 Piave points above $0.8 \mathrm{~m}$ (Table 1) of water depth were not considered. The lower error resulting seems to be erroneous if compared with the other survey. The reason is due to the bad luminosity conditions of the aerial photos. The different calibration point number among the different years and surveys at different water level, seems to suggest that: i) a minimum number of 200 - 250 calibration points for each water range level (with a step of $0.2 \mathrm{~m}$ ) seems able to guarantee an average error lesser than $\pm 0.2 \mathrm{~m}$, from 0 to $1.5 \mathrm{~m}$ of water depth; ii) between $1.5 \mathrm{~m}$ and $2 \mathrm{~m}$ of depth (the deepest range surveyed), the error is generally greater than $\pm 0.2 \mathrm{~m}$ and between $0.3-0.4$ with at least 250 calibration points; iii) the different "error" trend among the analysed rivers suggest that the error is not only in function with the different depth and calibration points, but also with the "photo conditions" such as luminosity, hour of fly, etc.

Other important rules to produce a reliable colour bathymetry are: i) commissioning LiDAR and aerial photo surveys with the lowest water

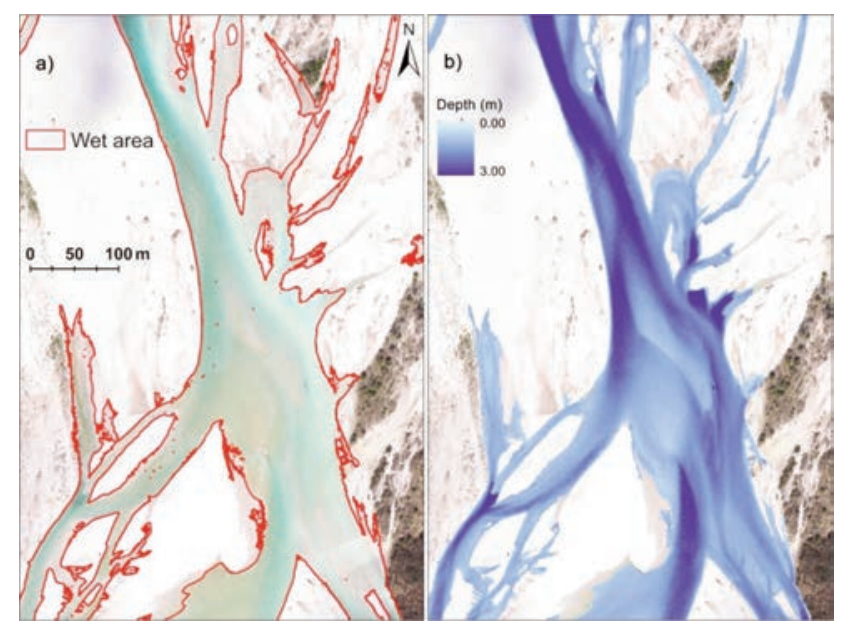

Figure 3. Wet area and colour bathymetry application on a sub-reach of Cornino 2011 (Tagliamento River).

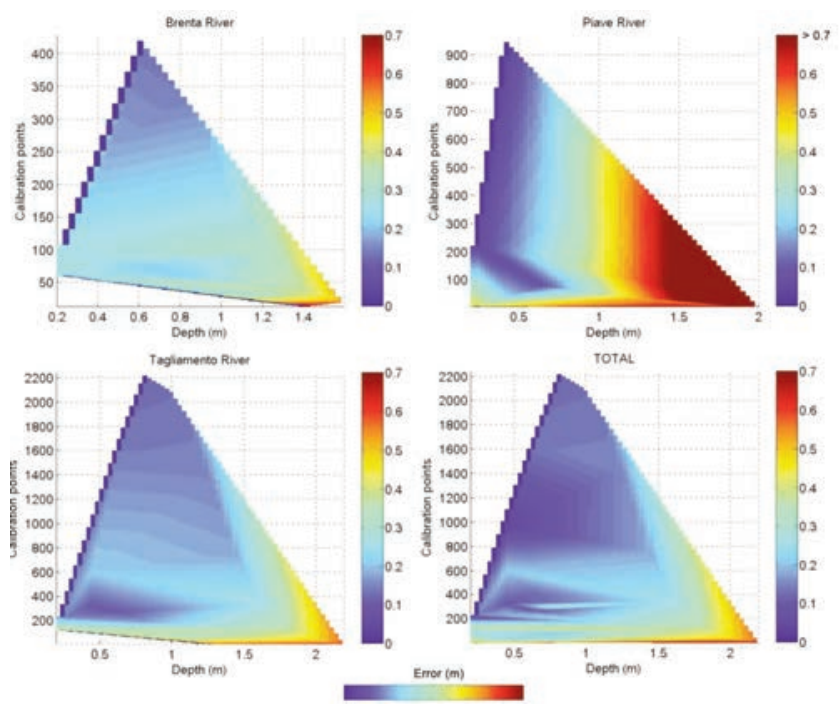

Figure 4. Error expected (with our surveys) at different water depth and number of calibration points. 


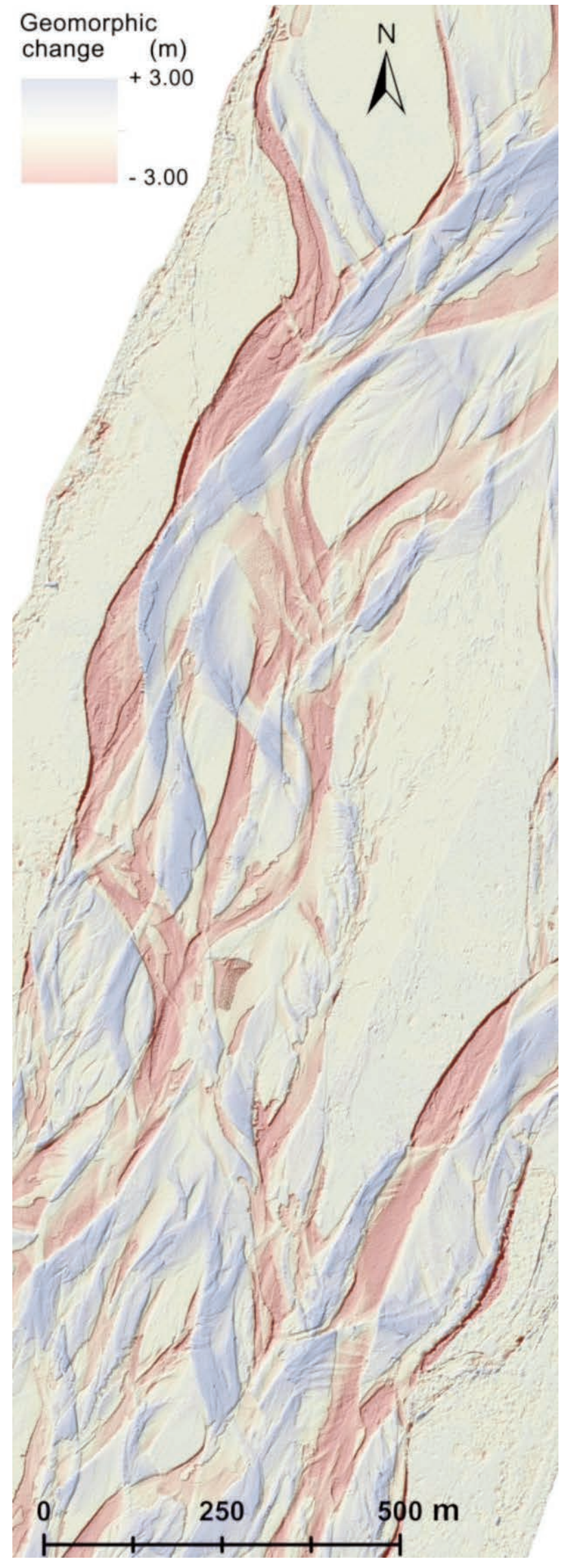

Figure 5. Difference of DEMs (DoD) of Cornino reach. depth and suspended sediment load; ii) flight time around midday, to avoid shadows which can introduce more errors on the colour models; iii) perfect photo-georeferenziation; iv) good water level estimation in the whole reach. Finally, an "ad-hoc" calibration of a depth-colour model, for each river and for each year, is necessary to have more precise water depth estimation. Indeed among different rivers and temporal surveys, change the luminosity condition, the channel bottom colour, the water turbidity and other factors that can change the colour at the same water depth.

However, thinking about a depth-colour model generalization, this work suggest that is important to use models with three colour bands (if we are using RGB photos) to allow a better colour combination and avoid as much as possible, the noise effects due for example, to the presence of pheriphyton in the bottom (Moretto et al., 2012). The depth-colour model could be calibrated by using all the data from each river and years together, but if we aim at precise volumetric change evaluation, as highlighted above, an ad-hoc calibration (depth models $2-7$ ) results more accurate.

The difference of DEM (DoD), is reported (Figure 5) for the Cornino reach, derived from the 2011 and 2010 HDTMs difference. These changes are due to the flood events of November-December 2010 (RI > 10 years). The most part of the variations have occurred in the wet areas; as highlighted in Moretto et al., 2012, Delai et al., 2013 and Moretto et al., 2013b. The results confirm that if we aim at geomorphic changes evaluation in environments with a significant presence of the wet areas, bathymetric techniques are required to not provide far results from the reality.

\section{Conclusions}

The proposed methodology allows the production of high-resolution DTMs of wetted areas with an associated uncertainty which is comparable to LiDAR data (Moretto et al., 2012). The statistical analyses have demonstrated that all the three colour bands (R, G, B), in all the three rivers are significantly related to water depth.

The different number of calibration points acquired (Table 1) also at different water level, has shown that the error of the colour bathymetry is significantly related to water depth and water stage.

A minimum number of 250 calibration points for each water range level (with a step of $0.2 \mathrm{~m}$ ) seems to be the threshold to guarantee an average error lesser than $\pm 0.2 \mathrm{~m}$ from 0 to $1.5 \mathrm{~m}$ of water depth.

The raster of difference (DoD) highlights the consequences of the flood events of November-December 2010 (RI > 10 years), indicating that deposition and erosion areas are more concentrated in the wet areas. In the analysis of braided morphologies, the calculation of not corrected estimations of change in those areas can lead to volumetric results far from the real values. The results of this study can be a valuable support to generate precise elevation models, also for the wet areas, that can be useful to evaluate erosion-deposition patterns, to improve sediment budget calculation, numerical modeling and to develop more effective river management strategies.

\section{References}

Burnham K.P., Anderson, D.R. 2002. Model Selection and Multimodel Inference: A Practical Information-Theoretic Approach. 2nd New York, ed. Springer, pp. 488.

Carbonneau P.E., Lane S.N., Bergeron N.E. 2006. Feature based image processing methods applied to bathymetric measurements from 
airborne remote sensing in fluvial environments. Earth Surface Processes and Landforms 31: 1413-1423.

Delai, F., Moretto, J., Picco, L., Rigon, E., Ravazzolo D., Lenzi, M.A. 2013. Analysis of Morphological Processes in a Disturbed Gravel-bed River (Piave River): Integration of LiDAR Data and Colour Bathymetry. Journal of Civil Engineering and Architecture, USA JCEA-E 20130528-4. (In press)

Hicks, D.M. 2012. Remotely sensed topographic change in gravel riverbeds with flowing channels. In Church M., Biron P.M., and Roy A.G. Gravel-bed Rivers: Processes, Tool, Environments. WileyBlackwell, pp. 303-314.

Lane S.N., Widdison P. E., Thomas R.E., Ashworth P.J., Best J.L., Lunt I.A., Sambrook Smith G.H., Simpson C.J. 2010. Quantification of braided river channel change using archival digital image analysis. Earth Surface Processes and Landforms 35: 971-985. D0I: 10.1002/esp.2015.

Legleiter, C.J. 2012. Mapping river depth from publicy available aerial images. River Research and Applications, doi: 10.1002/rra.2560

Legleiter, C.J., Kinzel, P.J., Overstreet, B.T. 2011. Evaluating the potential for remote bathymetric mapping of a turbid, sand-bed river: 1 . Field spectroscopy and radiative transfer modeling. Water Resour. Res., 47, W09531, doi:10.1029/2011WR010591.

Legleiter, C.J., Roberts, D.A. 2009. A forward image model for passive optical remote sensing of river bathymetry. Remote Sensing of Environment 113: 1025-1045.
Moretto, J., Rigon, Mao, L., E., Picco, L., Delai, F., Lenzi, M.A. 2013a. Channel adjustments and island dynamics in the Brenta River (Italy) over the last 30 years. River Research and Applications. (In press)

Moretto, J., Delai, F., Picco, L., Rigon, E., Ravazzolo D., Lenzi, M.A. 2013b. Integration of colour bathymetry, LiDAR and DGPS survey for assessing fluvial changes after floods events in the Tagliamento River (Italy). Agricultural Sciences. ISSN Print: 2156-8553. (In press)

Moretto, J., Rigon, E., Mao, L., Picco, L., Delai, F., Lenzi, M.A. 2012. Assessing morphological changes in gravel bed rivers using LiDAR data and colour bathymetry. IAHS-AISH Publication, Issue 356: 419-427.

Picco, L., Mao, L., Cavalli, E., Buzzi, E., Rigon, E., Moretto J., Delai F., Ravazzolo D., Lenzi M.A. 2012. Using a Terrestrial Laser Scanner to assess the morphological dynamics of a gravel-bed river. IAHSAISH Publication, Issue 356: 428-437.

Rennie, C.D. 2012. Mapping water and sediment flux distributions in gravel-bed rivers using ADCPs. Gravel-bed Rivers: Processes, Tool, Environments. Wiley-Blackwell, pp. 342-350.

Winterbottom, S.J., Gilvear, D.J. 1997. Quantification of channel bed morphology in gravel-bed rivers using airborne multispectral imagery and aerial photography. Regulated Rivers: Research and Management 13: 489-499. 